\title{
MTRA-Aktionstage 2015
}

Spannender Ausbildungsberuf zwischen Mensch und Technik stellt sich vor

Die Anmeldung für die MTRA-Aktionstage ist freigeschaltet: Im X-Ray-Monat November sollen sich wieder die Türen vieler MTRA-Schulen in ganz Deutschland öffnen. Interessierte Schulen können sich ab sofort über die Homepage www.mtawerden.de für die Teilnahme an den Aktionstagen anmelden und gemeinsam mit den Organisatoren des Projekts diesen Tag der offenen Tür ausrichten.
Die Vereinigung Medizinisch-Technischer Berufe in der DRG, die Deutsche Röntgengesellschaft e.V. und der Dachverband für Technologen/-innen und Analytiker/-innen in der Medizin Deutschland e.V. organisieren zum 7. Mal die MTRA-Aktionstage zusammen.

Alle Informationen und Formulare: 